\title{
The "Waiting Period" of Sensory and Motor Axons in Early Chick Hindlimb: Its Role in Axon Pathfinding and Neuronal Maturation
}

\author{
Guoying Wang and Sheryl A. Scott \\ Department of Neurobiology and Anatomy, University of Utah School of Medicine, Salt Lake City, Utah 84132
}

\begin{abstract}
During embryonic development motor axons in the chick hindlimb grow out slightly before sensory axons and wait in the plexus region at the base of the limb for $\sim 24 \mathrm{hr}$ before invading the limb itself (Tosney and Landmesser, 1985a). We have investigated the role of this waiting period by asking, Is the arrest of growth cones in the plexus region a general property of both sensory and motor axons? Why do axons wait? Does eliminating the waiting period affect the further development of motor and sensory neurons?

Here we show that sensory axons, like motor axons, pause in the plexus region and that neither sensory nor motor axons require cues from the other population to wait in or exit from the plexus region. By transplanting older or younger donor limbs to host embryos, we show that host axons innervate donor limbs on
\end{abstract}

a schedule consistent with the age of the grafted limbs. Thus, axons wait in the plexus region for maturational changes to occur in the limb rather than in the neurons themselves. Both sensory and motor axons innervate their appropriate peripheral targets when the waiting period is eliminated by grafting older donor limbs. Therefore, axons do not require a prolonged period in the plexus region to sort out and project appropriately. Eliminating the waiting period does, however, accelerate the onset of naturally occurring cell death, but it does not enhance the development of central projections or the biochemical maturation of sensory neurons.

Key words: waiting period; chick; hindlimb; axon pathfinding; neuron development; motor neuron; sensory; dorsal root ganglion; cell death; trkA; substance $P$; central projections
The overall time course and sequence of events in the development of motor (Landmesser, 1988, 1994) and sensory neurons (Scott, 1992a) has been described in detail, although the underlying regulatory mechanisms are far from understood. In the chick hindlimb, sensory axons grow out together with, but slightly later than, motor axons (Tosney and Landmesser, 1985a; Landmesser and Honig, 1986). Motor axons grow as far as the base of the limb and then pause for $24 \mathrm{hr}$ in the plexus region before growing into the limb itself (Tosney and Landmesser, 1985a). Within the plexus region the axons destined for particular peripheral targets come together, sort out, and make specific pathway choices (Lance-Jones and Landmesser, 1981; Tosney and Landmesser, 1985b,c). Both motor and sensory neurons project accurately to their appropriate peripheral targets from their earliest outgrowth (for review, see Landmesser, 1988, 1994; Scott, 1992b). Once axons reach their peripheral targets, both motor and sensory neurons undergo a period of programmed cell death that serves to match the size of the neuron population with its target (Oppenheim, 1991). Peripheral targets continue to influence the further differentiation of sensory neurons. For example, target muscles can determine the central projections of muscle afferents (Wenner and Frank, 1995). Moreover, cross-innervation studies in adult rodents show that the peripheral target can influence the biochemical phenotype of sensory neurons (McMahon and Gibson, 1987).

A remaining enigma in this well documented developmental sequence is the waiting period of axons as they invade the limb. The reasons for and the functional consequences of this waiting period are unknown. Whether the arrest of growth cones in the

Received March 8, 2000; revised April 24, 2000; accepted May 1, 2000.

This work was supported by National Institutes of Health Grant NS16107 to S.A.S We thank Drs. S. M. Cahoon-Metzger, M. L. Condic, and M. S. Rao for helpful comments on this manuscript. We also thank Dr. F. B. Lefcort for her generous gift of trk antibodies. Antibodies 3A10 (developed by Drs. T. M. Jessell and J. Dodd) and OCPN (developed by Drs. B. and J. Carlson) were obtained from the Developmental Studies Hybridoma Bank developed under the auspices of the National Institute of Child Health and Human Development and maintained by The University of Iowa, Department of Biological Sciences, Iowa City, IA 52242.

Correspondence should be addressed to Dr. Sheryl A. Scott, Department of Neurobiology and Anatomy, University of Utah School of Medicine, 50 North Medical Drive, Salt Lake City, UT 84132. E-mail: sheryl.scott@hsc.utah.edu.

Copyright (C) 2000 Society for Neuroscience 0270-6474/00/205358-09\$15.00/0 plexus region is a general property of both sensory and motor axons is unknown also. We have begun to investigate the waiting period in the context of the normal development of motor and sensory neurons. In particular, we have asked, Do sensory neurons also pause in the plexus region before invading the limb? Do neurons wait in the plexus region for maturational changes in the limb or in the neurons themselves? Do neurons require the waiting period to project accurately to their appropriate peripheral targets? How does elimination of the waiting period affect the further differentiation of the neurons? Our results indicate that sensory neurons, like motor neurons, pause for $\sim 1 \mathrm{~d}$ in the plexus region. An analysis of axon outgrowth in embryos with transplanted older limbs showed that axons wait in the plexus region for maturational changes to occur in the limb. Neither population, however, requires the waiting period to project accurately to its peripheral targets. Elimination of the waiting period, which results in precocious innervation of peripheral targets, accelerates the onset to naturally occurring cell death, but it does not influence the development of central connections or the maturation of some biochemical properties of sensory neurons.

Some of this work has been presented in abstract form (Scott and Wang, 1999; Wang and Scott, 1999a).

\section{MATERIALS AND METHODS}

\section{General}

Fertile White Leghorn chick eggs from a local supplier were incubated in a humidified forced-draft incubator at $38^{\circ} \mathrm{C}$. Embryos were staged according to Hamburger and Hamilton (1951) at the time of surgery and at death.

\section{Embryonic surgery}

Several types of surgical manipulations were performed on embryos between stage (St.) 15 and St. 22 [embryonic days 2.5-3.5 (E2.5-E3.5)]. A window was cut in the shell over the embryo. The vitelline and amniotic membranes over the posterior part of the embryo were torn open, and the area was stained lightly with $0.5 \%$ sterile neutral red in Ringer's solution (Scott, 1984). The desired portion of the tissue was excised with sharpened tungsten needles, as described below. The embryo was moistened with several drops of Ringer's solution. Eggs were sealed with paraffin and a coverslip and returned to the incubator until the desired stage.

Motor and sensory neuron removal. To test whether sensory neurons require motor neurons to wait in or exit from the plexus region, we eliminated motor neurons at St. 17-18 by aspirating the ventral two-thirds of the neural tube, leaving the dorsal one-third of the neural tube (includ- 
ing neural crest) intact, as described previously (Landmesser and Honig, 1986; Scott, 1988; Wang and Scott, 1999b). To test whether motor axon outgrowth is influenced by sensory axons, we eliminated sensory neurons by removing the neural crest at St. 15-16 (Scott, 1984), leaving the ventral neural tube intact.

Heterochronic limb transplantation. Older donor limb buds were prepared from St. 21-22 embryos by severing the limb bud adjacent to the lateral boundary of the somites. Then donor limb buds were transferred to younger (St. 17) host embryos from which one limb bud similarly had been removed. Conversely, younger limb buds were transplanted from St. 17-18 donors to older St. 21-22 hosts. In each case the undisturbed contralateral host limb bud served as a control for the grafted limb. As a further control, several St. 17 or St. 21 embryos received sham operations in which one limb bud was simply removed and replaced. Moreover, in a few donor embryos we removed the whole neural tube opposite somites 22-31 at St. $15-16$ before axon outgrowth. Denervated donor embryos were allowed to develop to St. 21-22, when their aneural limbs were transplanted to normal St. 17 hosts.

To determine the extent of limb tissue that was transplanted, in particular whether or not the plexus region was derived from transplanted or host tissue, in a few cases we transplanted an older quail limb bud onto a younger chick host. Embryos with obvious abnormalities or that did not fit the criteria described in Results were discarded.

\section{Retrograde labeling}

To analyze the peripheral and central innervation patterns in transplanted limbs, we retrogradely labeled sensory and/or motor neurons with DiI [2.5 $\mathrm{mg} / \mathrm{ml}$ in dimethylformamide (DMF); Molecular Probes; Eugene, OR] in operated embryos at St. 29-34. Embryos were removed from the eggs and placed in a bath of oxygenated Ringer's solution at room temperature. The embryos were decapitated and eviscerated, and a ventral laminectomy was performed. Dorsal root ganglia (DRGs) from the last thoracic (T7) to the fourth lumbosacral (LS4) segment or selected hindlimb muscles (sartorius, femorotibialis, or adductor) were exposed and injected with DiI. After injection the embryos were maintained in oxygenated Ringer's solution at $28^{\circ} \mathrm{C}$ for $6 \mathrm{hr}$, when they were fixed in $4 \%$ paraformaldehyde. Then the embryos were stored in paraformaldehyde at $37^{\circ} \mathrm{C}$ for another $2-3$ weeks to allow for thorough retrograde labeling.

Injected embryos were observed first as whole mounts with fluorescence optics to assess the overall pattern of transported dyes. Subsequently, a region of the embryo containing the spinal cord and DRGs from T6 through the lumbosacral enlargement was cut out and embedded in gelatin-albumin. Blocks were hardened overnight with $1 \%$ glutaraldehyde and serially sectioned at $80 \mu \mathrm{m}$ with a vibratome. To observe the mediolateral distribution of motor neurons and the central projections of sensory neurons in the spinal cord, we cut the blocks transversely; to observe the segmental distribution of motor and sensory neurons, we cut other blocks longitudinally. Sections were mounted in $90 \%$ glycerol $/ 10 \%$ PBS containing $0.1 \% p$-phenylenediamine (Johnson and Nogueira Araujo, 1981) to retard fading. Labeling was viewed with a Zeiss Axioskop microscope or an Olympus Fluoview confocal scanning laser microscope.

\section{Immunohistochemistry}

To distinguish between sensory and motor axons in single sections, we double-labeled sections, using one antibody that stains all axons [3A10, 1:100; Developmental Studies Hybridoma Bank (DSHB), University of Iowa, Iowa City, IA] and a second antibody that labels only sensory axons (anti-trkC; kindly provided by Dr. F. B. Lefcort, Department of Biology, Montana State University, Bozeman, MT). Axons that stained with 3A10, but not with anti-trkC, were considered to be motor neuron axons. Quai cells were identified with QCPN (1:50; DSHB). To examine the biochemical maturation of sensory neurons, we stained sections with anti-substance P (1:200; PharMingen, San Diego, CA) or anti-trkA (1 $\mu \mathrm{g} / 7 \mathrm{ml}$; provided by Dr. Lefcort).

Normal and operated embryos from St. 20-26 were fixed in 4\% paraformaldehyde for several hours to overnight (depending on the stage), cryoprotected in $20 \%$ sucrose in PBS, and sectioned with a cryostat. For staining with all antibodies except anti-trk, the sections were incubated for $1 \mathrm{hr}$ at room temperature in PBS containing 5\% normal goat serum (NGS) and $0.1 \%$ Triton $\mathrm{X}-100$. Then the sections were incubated at $4{ }^{\circ} \mathrm{C}$ overnight in primary antibody diluted in the same buffer. Immunoreactivity was detected by using FITC, rhodamine, and/or Texas Red-conjugated secondary antibody. Anti-trkC and anti-trkA staining was amplified with Tyramide Signal Amplification (TSA, New England Nuclear, Boston, MA).

\section{Cell death}

To analyze cell death of motor and sensory neurons in embryos with heterochronic limb transplants, we fixed embryos from St. 28-36 in Bouin's solution for at least $24 \mathrm{hr}$, dehydrated them in graded ethyl alcohol, and embedded them in paraffin. Transverse $8-10 \mu \mathrm{m}$ sections were stained with cresyl violet or thionine. In one-half of the operated embryos motor neurons were counted in every tenth section of both sides of the embryo from segment LS1 through LS8, as described by Clarke and Oppenheim (1995). In the other half the motor neurons were counted only in segment LS3. To estimate the size of DRGs, which was taken as an indication of sensory neuron number, we measured the diameter of the largest profile of

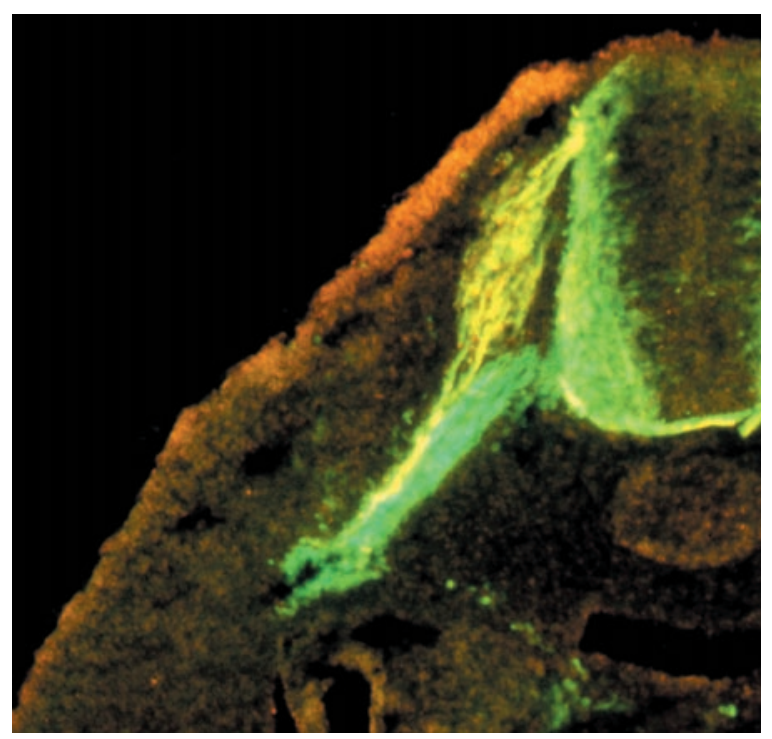

Figure 1. Sensory axons grow out slightly later than motor axons. Shown is a transverse section through the spinal cord and plexus region of a St. 22 embryo stained with $3 \mathrm{~A} 10$ to label all neurons and stained with anti-trkC to label sensory neurons. Motor axons are labeled only with 3A10 and appear green; sensory axons are double-labeled and appear yellow. Note that sensory axons lag only slightly behind motor axons.

the LS3 DRG on both the experimental and control sides, using Image-1 software (Universal Imaging, West Chester, PA).

In addition, apoptotic motor and sensory neurons were identified with TUNEL staining in paraffin sections by using an In Situ Cell Death Detection kit (catalog \#1684795, Roche Molecular Biochemicals, Indianapolis, IN). Labeled motor and sensory neurons were counted in every third section throughout segment LS3 on both sides of the embryo.

\section{RESULTS}

\section{Sensory and motor axon outgrowth through the plexus region}

\section{Normal axon outgrowth}

During normal development the motor axons grow as far as the base of the hindlimb and then pause for $24 \mathrm{hr}$ in the plexus region before invading the limb itself (Tosney and Landmesser, 1985a). To determine whether sensory axons, which grow out slightly later than motor axons (Tosney and Landmesser, 1985a; Landmesser and Honig, 1986) (Fig. 1), also wait in the plexus region, we compared the time course of sensory axon growth into the limb with that of all axons and of motor neurons in embryos from St. 20-25. Sensory axons were identified with anti-trkC, as described in Materials and Methods.

The pattern of early sensory axon growth closely parallels that of all axons. Outgrowth of sensory axons from rostral lumbosacral dorsal root ganglia (DRGs LS1-3) is obvious by St. 21, and many axons have arrived at the plexus region by St. 22 (Fig. $2 D$ ). They did not emerge from the plexus region and enter the limb proper until late St. 24 (Fig. 2E,F). Thus, sensory axons like motor axons wait in the plexus region for $\sim 24 \mathrm{hr}$ before advancing into the limb.

\section{Sensory axon outgrowth in the absence of motor neurons}

Both anatomical evidence (Tosney and Landmesser, 1985b) and experimental evidence (Landmesser and Honig, 1986; Scott, 1988) suggest that motor axons may direct sensory axon outgrowth. Thus, sensory axon growth may be arrested in the plexus region simply because motor axons pause there for $1 \mathrm{~d}$. To test this possibility, we removed motor neurons at St. 17, before axon outgrowth, and charted the timing of sensory axon outgrowth in the absence of motor neurons. Fifteen of the 70 operated embryos survived and were missing motor neurons from at least segments LS1-3. No ventral horn formed in the operated region, but DRGs developed normally (arrows, Fig. 2G-I).

Sensory axon outgrowth in the absence of motor neurons was 

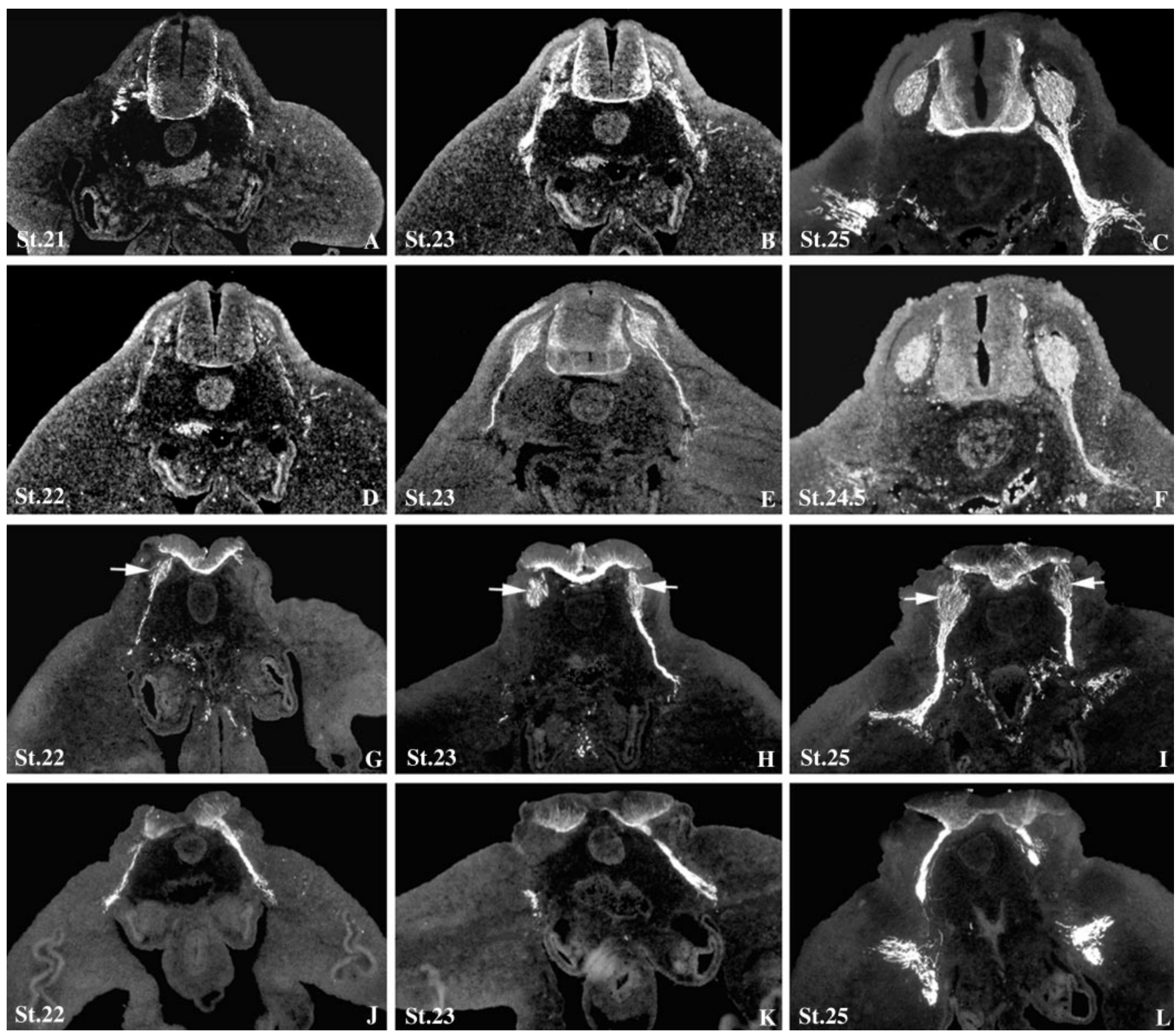

Figure 2. Transverse sections through embryos of different stages show the timing of sensory and motor axon outgrowth. $A-C$, Sections stained with 3 A 10 to show normal outgrowth of all axons (both sensory and motor). $D-F$, Sections stained with trkC to show normal outgrowth of sensory axons. $G-I$, Sensory axon outgrowth in the absence of motor neurons. After early removal of the ventral neural tube the lateral motor column is missing, but DRGs (arrows) still develop. $J-L$, Outgrowth of motor axons in the absence of sensory neurons. After neural crest removal, DRGs are missing, but the lateral motor column develops normally. Note that axon outgrowth in each condition is similar to that of the normal control axons shown in the top row.

indistinguishable from normal. Sensory axons reached the plexus region at approximately St. 21 (data not shown) and accumulated in this region during St. 22 (Fig. $2 G$ ) and St. 23 (Fig. 2H). They began to exit the plexus region late in St. 24 (data not shown) and clearly had begun to grow into the limb by St. 25 (Fig. 2I). Moreover, in the absence of motor neurons the sensory axons diverged into dorsal and ventral branches like normal. Thus, sensory axons can grow to the plexus region, pause there, and exit appropriately from this region on schedule without cues from neighboring motor neurons.

\section{Motor axon outgrowth in the absence of sensory neurons}

Because sensory axons grow out slightly later than motor axons (Tosney and Landmesser, 1985a; Landmesser and Honig, 1986) (see Fig. 1), we asked whether motor axons pause to allow sensory axons to catch up before invading the limb. To approach this question, we eliminated sensory neurons by removing the dorsal half of the neural tube including the neural crest opposite somites 22-31 at St. 15-16, leaving the ventral neural tube intact, and charted the time course of motor axon outgrowth. Seven of the 15 operated embryos survived and were missing DRGs LS1-3 (or more). As illustrated in Figure $2 J-L$, in the absence of sensory neurons the motor axons grew out, paused, and invaded the limb normally.

\section{Sensory and motor axon outgrowth after heterochronic limb transplantation}

Together, these results show that sensory and motor axons can grow to, wait in, and exit from the plexus region independently of each other. We next asked why these axons wait in the plexus region and what allows them to leave. Are outgrowing axons too immature to respond to permissive cues in the limb, or is the limb itself not yet favorable for axon growth? To distinguish between these possibilities, we analyzed axon growth and the waiting period in embryos in which we grafted an older St. 21-22 limb bud onto a younger St. 17 host. If axons from younger embryos grow directly into the older limb without stopping in the plexus region, this would suggest that axons pause to allow maturational changes to 

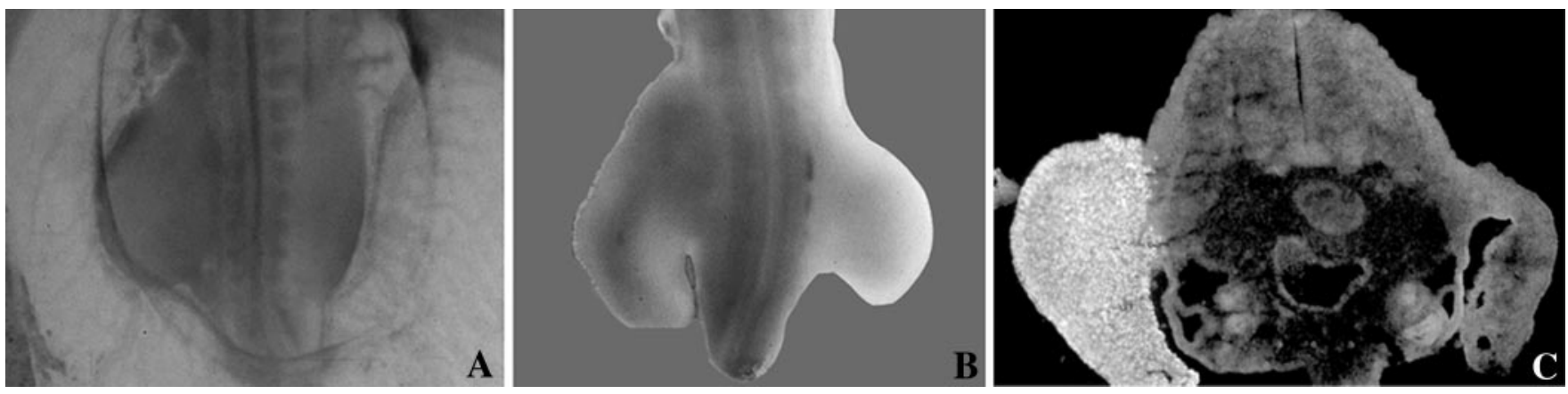

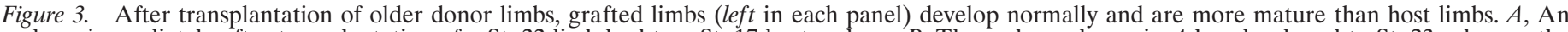

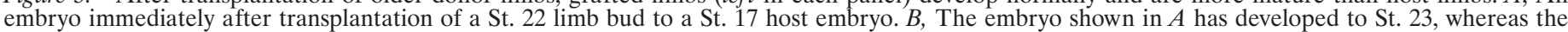

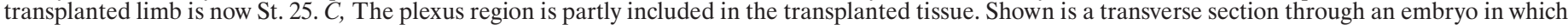
a quail limb bud was transplanted to a younger chick host. Quail tissue is identified with antibody QCPN.
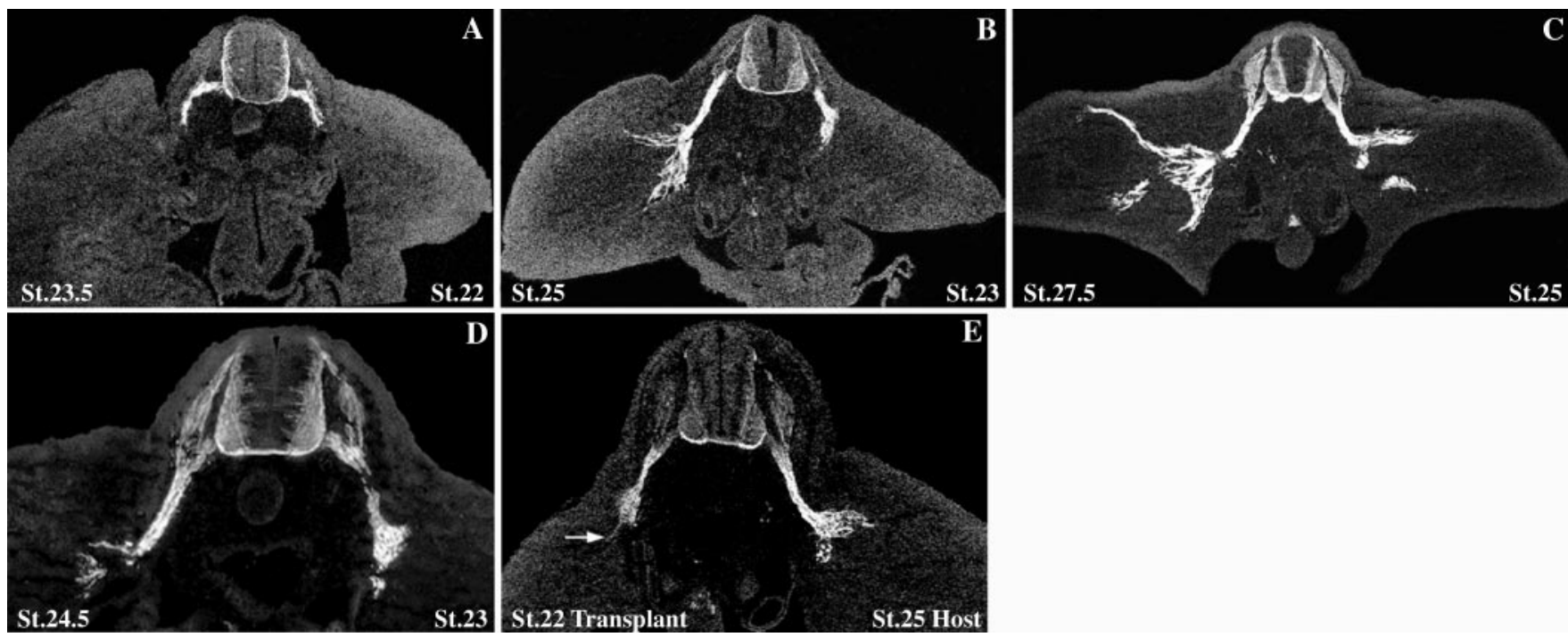

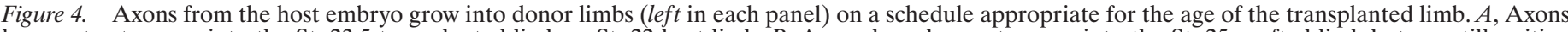

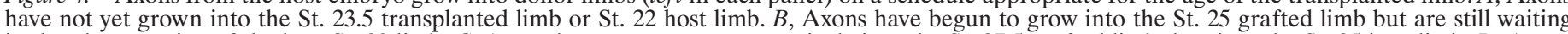

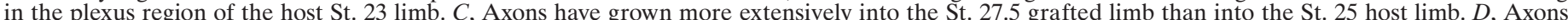

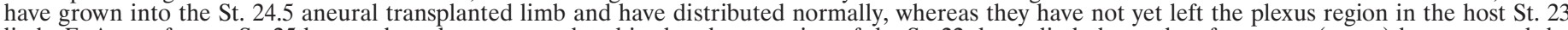

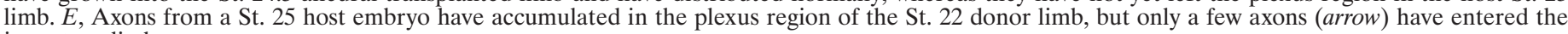
immature limb.

occur in the limb. Conversely, failure of axons to invade the older limb until the host reaches St. 24-25 would suggest that younger axons are incapable of responding to cues from the limb, and the waiting period enables maturational changes to occur in the axons.

Eighty-five of the 260 operated embryos survived and had normal-appearing transplanted limbs. Embryos in which the transplanted limb was deformed or developed a hemorrhagic clot were discarded. In addition, five chick hosts successfully received quail limb bud transplants. Further, 14 St. 17-18 embryos, all of which survived, received sham operations in which the limb bud simply was removed and replaced.

As described previously (Swanson and Lewis, 1982), the grafted hindlimbs developed according to their own autonomous timetable. Thus, at the time of analysis the grafted limb was larger and one to three stages more mature than the host limb, as illustrated in Figure 3, $A$ and $B$. However, because early developmental stages are shorter than later stages, as the embryos matured the absolute difference in the number of stages between the host and grafted limbs became smaller. Anti-quail antibody staining showed that the entire limb, including part of the plexus region, was derived from transplanted tissue (Fig. $3 C$ ). Thus, axons from the host embryo encountered older, more mature tissue as they exited from the plexus region and entered the transplanted donor limb.

The initial outgrowth of axons toward the plexus region was nearly identical on both the operated and control sides of the embryo. For example, in the embryo shown in Figure $4 A$ (St. 22 host: St. 23.5 graft), axons have reached the plexus region but have not entered either limb. Similar results were obtained in four additional embryos in which the donor limb was St. 24 or younger. Analysis of slightly older embryos showed that axons innervated grafted limbs on a schedule dictated by age of the limb rather than the age of the host, as illustrated in Figure $4 B$. In this embryo the axons have grown into the grafted St. $25 \mathrm{limb}$ but still are waiting like normal in the plexus region of the St. 23 host limb. Innervation of the grafted and host limbs is indistinguishable from innervation of normal St. 25 and St. 23 limbs, respectively. Similar results were obtained in three other St. 23 host: St. 25 transplant embryos. This pattern was maintained at later stages; innervation of donor limbs (St. 27-28) was more extensive than that of the younger hosts (St. 25-26) $(n=5$; Fig. 4C), as previously reported (Swanson and Lewis, 1982).

Together, these results suggest that axons wait in the plexus region for maturational changes to occur in the limb. However, the plexus region in donor limbs already had been invaded by axons when the limb bud was excised. This early innervation could alter the plexus region, thereby allowing host axons to exit prematurely after heterochronic transplantation. To eliminate this possibility, we transplanted aneural St. 21 limb buds (see Materials and Meth- 

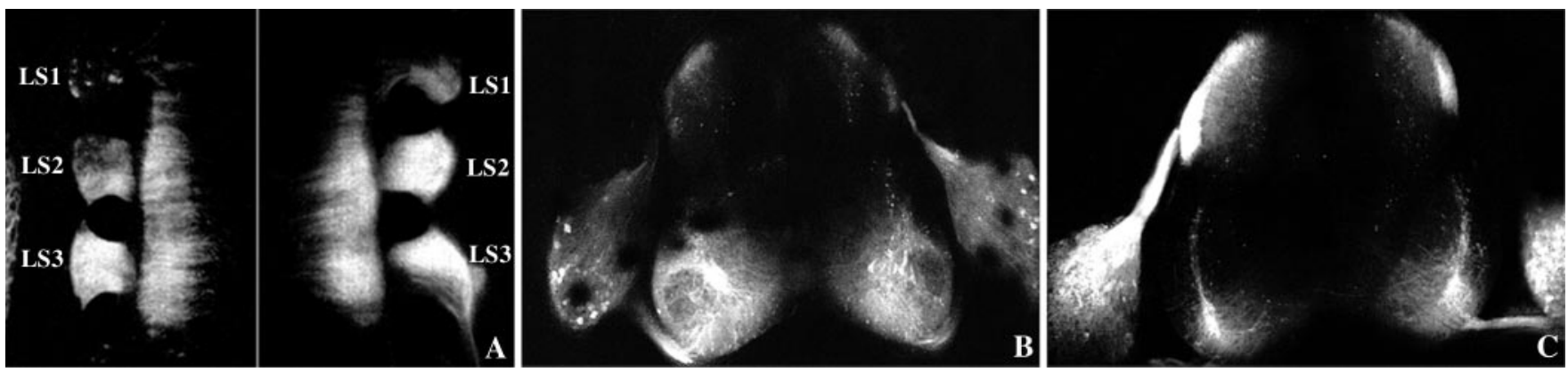

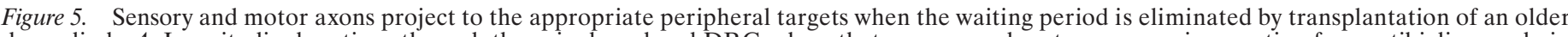

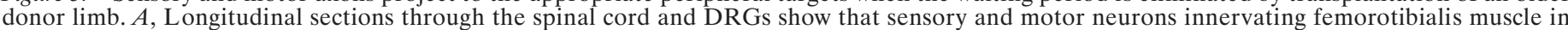

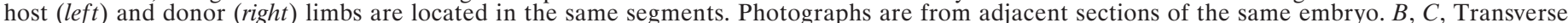

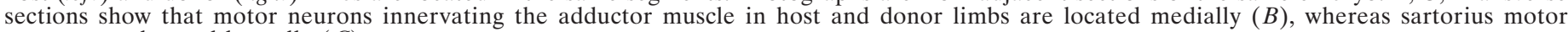
neurons are located laterally $(C)$.

ods) to normal St. 17 hosts. In all six embryos that were examined, axons innervated the donor limb on a schedule appropriate for the transplanted limb (Fig. 4D). Moreover, axons diverged into dorsal and ventral bundles, as in normal embryos. Thus, the accelerated innervation of grafted older limbs does not result from their previous innervation.

To test further whether the waiting period is attributable to maturational changes in the neurons or in the limb, in a few cases we grafted younger limb buds onto older donor embryos $(n=7)$. From the results described above, we expected that host axons would wait in the plexus region until the transplanted limb reached St. 24-25, regardless of the age of the host. Indeed, most host axons grew out and accumulated in the plexus region of the younger transplanted limb. However, a few axons escaped this region and projected into the grafted limb despite its relatively immature age, as shown in Figure $4 E$. Nevertheless, innervation of these young limbs always lagged behind that of the older host limb. Further examination of control embryos receiving sham operations at St. 21 (see below) indicated that this operation resulted in the death of some host neurons, most likely neurons whose axons were severed during surgery. Thus, embryos in which younger limb buds were transplanted onto older hosts were not studied further.

\section{Specificity of sensory and motor neuron projections after heterochronic limb transplantation}

During normal development the axons from different segmental levels come together within the plexus region and sort out before projecting selectively to their respective peripheral targets (Tosney and Landmesser, 1985b). As described above, we have shown that the waiting period of axons in the plexus region essentially can be eliminated by transplanting an older limb bud onto a younger host embryo. In these embryos the axons grow into the transplanted limb with little or no delay. Thus, we have used this preparation to ask whether the waiting period is essential for motor and sensory neurons to establish their appropriate peripheral projections.

To investigate this, we injected DiI into the sartorius, femorotibialis, or adductor muscle of eight embryos with grafted limbs that were one to two stages older than their St. 30-32 hosts. The rostrocaudal distributions of labeled sensory and motor neurons innervating host and donor muscles were identical, as shown in the longitudinal section in Figure $5 A$. Similar results were obtained in one additional embryo sectioned longitudinally and in six embryos sectioned transversely. Moreover, the transverse sections of operated embryos showed that the mediolateral distribution of motor neurons innervating transplanted limbs was also normal. For example, adductor motor neurons innervating host and donor limbs were located medially (Fig. $5 B$ ), whereas sartorius motor neurons were located laterally (Fig. 5C). Thus, the peripheral projections of motor and sensory neurons are established appropriately when axons grow into the limb without first pausing within the plexus region. The possibility exists, however, that there are subtle changes in innervation patterns [for example, changes in spatial relationships among sensory and motor axons in peripheral nerves (Honig et al., 1998)] when the waiting period is eliminated. Such changes would not have been detected with the techniques used here.

\section{Maturation of motor and sensory neurons after premature innervation of peripheral targets}

Sensory and motor axons grow into grafted limbs several stages earlier than into host limbs after heterochronic transplantation of older donor limbs. To determine whether this premature innervation of peripheral targets accelerates neuronal maturation, we analyzed three aspects of neuronal development in operated embryos-programmed cell death, the development of central projections of sensory neurons, and the biochemical maturation of sensory neurons.

\section{Programmed cell death}

A cursory examination of transverse sections of operated embryos suggested that premature innervation of grafted limbs affected programmed cell death. The lateral motor column (LMC) and DRGs that innervated older, donor limbs appeared smaller than the respective control neuron populations (Fig. $6 A-D$ ). In contrast, the size of the LMC and DRGs was similar on the two sides of sham-operated embryos (data not shown), indicating that the apparent reduction in the size of the LMC and DRGs after heterochronic limb transplants resulted from the early innervation of targets in older donor limbs rather than from the surgery itself. To quantify these apparent differences, we counted surviving motor neurons in the LMC throughout the entire lumbosacral region in six embryos and in segment LS3 in five additional embryos (Table 1). Cell counts confirmed that at most stages that were examined fewer motor neurons innervated the older transplanted limb. The difference in the number of motor neurons innervating the two limbs was not distributed across the entire LS region but instead was concentrated within one to two spinal segments in each embryo, again suggesting that this difference was not simply an artifact of surgery. There was a tendency for the biggest differences between control and experimental LMC to occur at more rostral segmental levels in younger embryos and at progressively more caudal levels in progressively older embryos, mirroring the normal rostrocaudal progression of cell death (Gould et al., 1999). For example, in embryo WP110 (St. 28: St. 29) the greatest difference occurred in segment LS1 (host/graft $=1.23$ ), whereas in embryo WP174 (St. 36: St. 36+) the greatest difference occurred in segment LS7 (host/graft $=1.68$ ). Moreover, examination of the LMC in a single segment, such as LS3, suggested that cell death occurred independently in control and experimental LMC but that programmed cell death had a head start on the experimental side. The difference in the number of LS3 motor neurons innervating host and donor limbs in very young or relatively old embryos was negligible, but it was significant at St. $30-32$ ( $p=0.003$; paired Student's $t$ test). These results are explained most easily if cell 

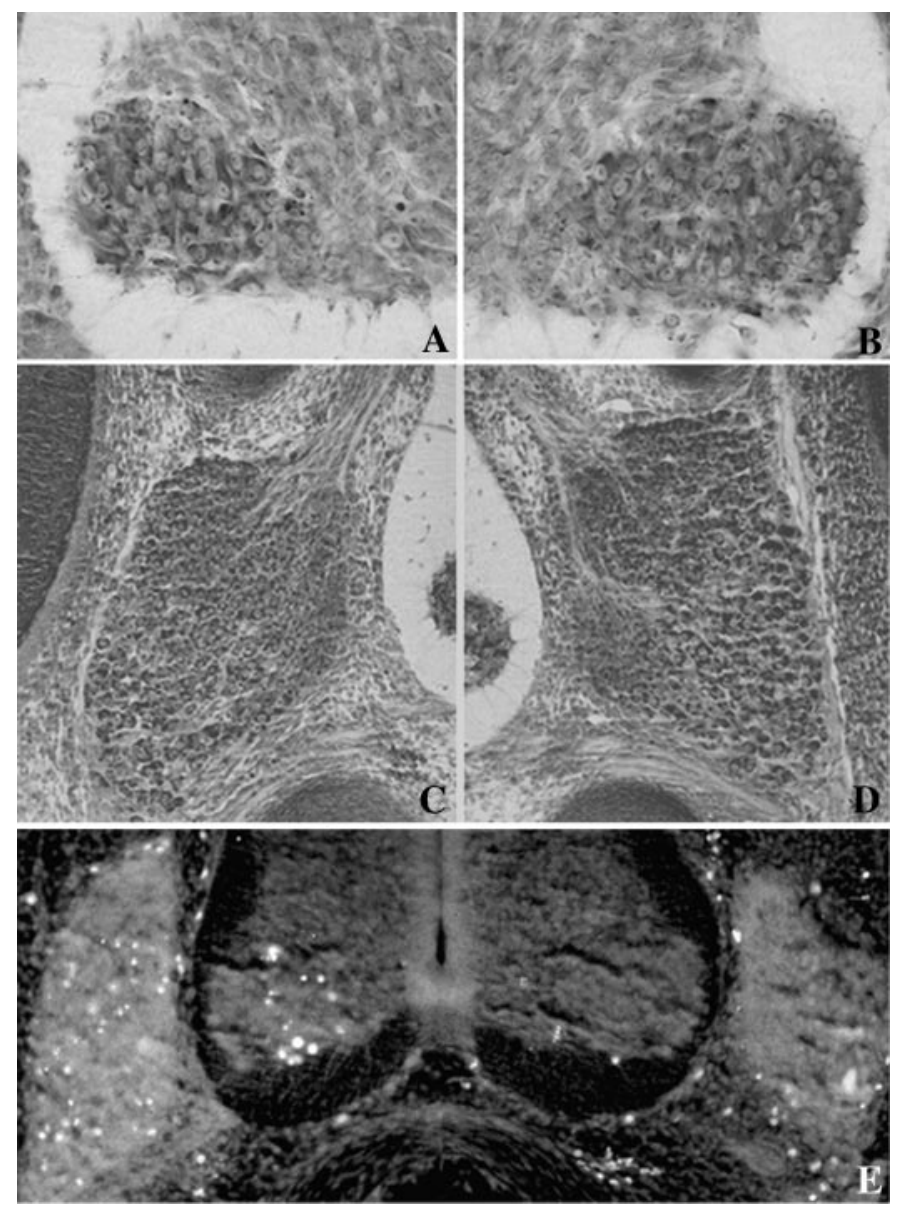

Figure 6. Innervation of older donor limbs accelerates the onset of naturally occurring cell death among motor $(A, B)$ and sensory $(C, D)$ neurons. Both the lateral motor column $(A)$ and DRGs $(C)$ that innervate older donor limbs $(A$, St. 32; $C$, St. 33$)$ are smaller than those innervating the respective control host limbs $(B$, St. $30 ; D$, St. 31$) . A$ and $B$ are from a single representative section of segment LS3. $C$ and $D$ show the largest profile of DRG LS3 on each side of one operated embryo. There were no differences in the size of the lateral motor column or DRGs after sham operations (data not shown). E, TUNEL staining of a transverse section through a St. 29 embryo with an older donor St. $32 \mathrm{limb}$ (left). Apoptotic motor and sensory neurons are more abundant among neurons innervating the older donor limb.

death had not yet begun at LS3 in the youngest embryos, was well underway among motor neurons innervating St. 31-32 donor limbs, and was complete on both sides of the oldest embryos.

Sensory neuron survival was assayed by measuring the diameter of the largest profile of DRG LS3 on both sides of all operated embryos. On average, DRG LS3 was $\sim 10 \%$ larger on the control side (Table 1), suggesting that cell death also began earlier among sensory neurons innervating older donor limbs.

To verify that programmed cell death indeed did occur earlier in neurons innervating older limbs, we performed TUNEL staining on sections of four embryos with grafted older limbs. Apoptotic cells were observed in the LMC and DRGs on the operated side before the onset of cell death on the control side, and apoptotic cells were more abundant in the LMC and DRGs on the operated side at all stages that were examined (St. 28-St. 32) (Fig. 6E, Table 2).

Together, these results show that early target innervation accelerates the onset of programmed cell death. Possible mechanisms responsible for triggering cell death prematurely are discussed below. Similar analyses were not performed in embryos with transplanted younger limbs, because motor neurons were depleted after sham operations performed at St. 21-22.

\section{Central projections and biochemical maturation of sensory neurons}

It is well established that peripheral targets can influence the development and specificity of central connections of muscle afferents (Wenner and Frank, 1995). Thus, we asked whether premature innervation of peripheral targets also accelerates the establishment of central projections of sensory neurons. To test this possibility, we injected DiI into individual muscles $(n=8)$ or DRGs $(n=8)$ in embryos with grafted older limbs and examined the central projections of sensory neurons in transverse sections. During normal development sensory afferents at lumbosacral levels begin to arrive at the edge of the spinal cord (the dorsal root entry zone, or DREZ) by St. 25 but do not grow appreciably into the future gray matter until after St. 30 (Lee et al., 1988; Davis et al., 1989; Sharma et al., 1994). The development of central projections followed this time schedule on both control and operated sides, despite the fact that sensory neurons reached their peripheral targets several stages earlier on the operated side. For example, as shown in Figure $7 A$, sensory axons have not left the DREZ on either side of this St. 29 embryo, although they innervate a St. 31 transplanted limb. At later stages, once axons begin to invade the gray matter, the central projections are nearly identical on both sides, as illustrated in Figure $7 B$ (St. 32 host: St. 34 graft). Similar results also were observed in the eight other embryos that were examined for selectivity of peripheral projections (see above).

Several biochemical markers of sensory neurons begin to appear at approximately the time that axons reach their peripheral targets, suggesting that the acquisition of these markers may be triggered by target innervation. For example, substance P (New and Mudge, 1986) and trkA (this study) are first detectable in lumbosacral DRGs at approximately St. 24-25, and staining becomes more robust at later stages. To investigate whether the appearance of these biochemical markers can be accelerated by early innervation of peripheral targets, we stained frozen sections of embryos with heterochronic limb transplants with anti-substance P and anti-trkA at selected embryonic stages. There was no obvious difference in expression of either substance $\mathrm{P}$ (Fig. $7 C$ ) or trkA (Fig. 7D) in DRGs on the host and experimental sides, although these DRGs innervated St. 25-26 and St. 27-28 limbs, respectively.

\section{DISCUSSION}

Although "waiting periods" have been well documented in several systems (Tosney and Landmesser, 1985a; Shatz et al., 1990; Sharma and Frank, 1994), neither their underlying mechanisms nor their functional significance is well understood. The experiments described here address these issues for sensory and motor axons that wait in the plexus region of the hindlimb during embryonic development. By transplanting older or younger donor limbs to host embryos, we have shown that axons wait in the plexus region for maturational changes to occur in the limb rather than in the neurons themselves. Neither sensory nor motor axons require a prolonged delay in the plexus region to project to their appropriate peripheral targets. Furthermore, our results suggest that premature target contact can accelerate the onset of programmed cell death but does not enhance the development of central connections or biochemical maturation of sensory neurons.

\section{Functional significance of the waiting period}

\section{Timing of sensory and motor outgrowth}

Tosney and Landmesser (1985a) first described the waiting period of motor axons in the plexus region in the chick hindlimb. Their observation that outgrowth of sensory axons lags behind that of motor axons (see Fig. 1) suggested, however, that sensory axons might enter the limb without pausing in the plexus region. We have shown that this is not the case. Sensory axons reach the plexus region only slightly later than motor axons, wait for $\sim 1 \mathrm{~d}$, and then advance into the limb with the motor axons. Moreover, by eliminating either motor or sensory neuron precursors, we have shown that the timing of outgrowth of each population is unaffected by the presence or absence of the other. These observations are consistent 
Table 1. Relative number of motor and sensory neurons innervating older donor and host limbs

\begin{tabular}{|c|c|c|c|c|}
\hline \multirow[b]{2}{*}{ Embryo } & \multirow[b]{2}{*}{$\begin{array}{l}\text { Limb stages } \\
\text { Host:Grafted }\end{array}$} & \multicolumn{3}{|l|}{ Host/Grafted } \\
\hline & & $\begin{array}{l}\text { Motor neurons } \\
\text { in LS1-LS8 }\end{array}$ & $\begin{array}{l}\text { Motor neurons } \\
\text { in LS3 }\end{array}$ & DRG LS3 \\
\hline WP 97 & St. 27:St. 29 & - & 1.03 & 1.15 \\
\hline WP 110 & St. 28:St. 29 & 1.05 & 1.11 & 1.05 \\
\hline WP 148 & St. 30:St. 31 & 1.08 & 1.23 & 1.27 \\
\hline WP 101 & St. 30:St. 31 & 1.10 & 1.14 & 1.26 \\
\hline WP 120 & St. 30:St. 31 & - & 1.15 & 1.17 \\
\hline WP 122 & St. 30:St. 31 & - & 1.34 & 1.12 \\
\hline WP 135 & St. 31:St. 32 & - & 1.79 & 1.36 \\
\hline WP 136 & St. 31:St. 33 & 1.13 & 1.22 & 1.09 \\
\hline WP 149 & St. 30:St. 32 & 1.14 & 1.16 & - \\
\hline WP 167 & St. $36:$ St. $36+$ & - & 1.04 & 1.11 \\
\hline WP 174 & St. 36:St. 36+ & 1.08 & 0.98 & 0.90 \\
\hline Sham 3 & St. 30:St. 30 & 1.03 & 1.04 & 1.00 \\
\hline Sham 4 & St. 32:St. 32 & 0.99 & 1.00 & 1.04 \\
\hline
\end{tabular}

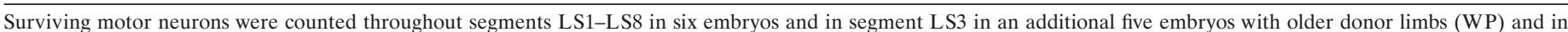

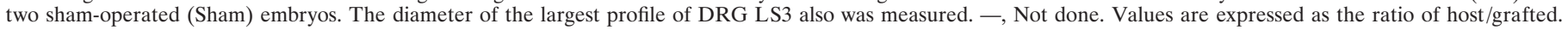

Table 2. Relative number of apoptotic motor and sensory neurons in embryos with older donor limbs

\begin{tabular}{|c|c|c|}
\hline \multirow[b]{2}{*}{ Embryo } & \multicolumn{2}{|l|}{ Limb stages } \\
\hline & $\begin{array}{l}\text { Grafted: } \\
\text { Host }\end{array}$ & Grafted/Host \\
\hline \multicolumn{3}{|c|}{ Motor neurons } \\
\hline WP 142 & St. 31:St. 29 & 2.59 \\
\hline WP 145 & St. 30:St. 28 & 3.14 \\
\hline WP 160 & St. 31:St. 28 & 5.06 \\
\hline Sham 7 & St. 28:St. 28 & 0.88 \\
\hline \multicolumn{3}{|c|}{ Sensory neurons } \\
\hline WP 142 & St. 31:St. 29 & 3.76 \\
\hline WP 160 & St. 31:St. 28 & 7.25 \\
\hline WP 161 & St. 30:St. 28 & 1.60 \\
\hline Sham 7 & St. 28:St. 28 & 1.09 \\
\hline
\end{tabular}

Apoptotic motor and sensory neurons identified with TUNEL staining were counted in segment LS3 in four embryos with older donor limbs (WP) and in one control sham-operated embryo and were expressed as the ratio of grafted/host.

with our previous findings that sensory and motor innervation patterns can develop independently in embryonic chick hindlimbs (Wang and Scott, 1999b).

\section{What cues are responsible for the waiting period?}

Why do axons wait in the plexus region and what allows them to leave? One possibility is that outgrowing axons are too immature to respond to permissive cues in the limb. Alternatively, the limb may not yet be favorable for axon growth. Our data from heterochronic limb transplants support the latter hypothesis. Axons from host embryos innervated donor limbs on a schedule dictated by the age of the limb. This finding is consistent with previous work by Swanson and Lewis (1982), who mapped innervation patterns in embryos after heterochronic wing transplants. Our studies, however, focused on the initial ingrowth of axons into the limb, whereas the earlier studies examined embryos at stages when innervation patterns were well established. Thus, we have shown that the accelerated development observed in earlier studies is attributable to axons growing into older donor limbs without first pausing in the plexus region.

Our findings are also consistent with the observation that in vitro motor neurons will not grow on slices of limb taken from St. 22 embryos, but they will grow readily on slices from older embryos
(Landmesser, 1988), as if the younger limb tissue either lacks attractive factors or expresses inhibitory factors.

The molecular nature of the signals that permit axons to leave the plexus region and invade the limb is unknown. Candidates include inhibitory and permissive molecules for which the expression pattern changes at approximately the time that axons grow into the limb [e.g., chondroitin-6-sulfate (Oakley and Tosney, 1991), ephA7 (Araujo et al., 1998), semaphorin III (Wright et al., 1995), various isoforms of laminin (Lentz et al., 1997)]. Clearly, discovering the signals that control axon growth into the limb and the mechanisms that regulate their expression is a challenging task.

\section{Functional consequences of eliminating the waiting period}

\section{Specificity of target innervation}

The plexus is an important region in which axons destined for individual targets come together, sort out, and make specific pathway choices (Lance-Jones and Landmesser, 1981; Tosney and Landmesser, 1985b,c). During normal development axons spend $\sim 1 \mathrm{~d}$ in the plexus region before projecting to their respective targets. Here we have shown that this prolonged delay is not required for axons to project accurately to their appropriate peripheral targets. The distributions of motor and sensory neurons retrogradely labeled from individual muscles in host and older transplanted limbs were indistinguishable, despite the fact that axons grew into the donor limbs with little or no delay. Whether the waiting period can be eliminated in other systems without affecting the accuracy of target innervation is unknown.

\section{Neuronal maturation}

After transplantation of older donor limbs, host neurons project to limbs that are one to three stages more mature than host limbs. Because peripheral targets clearly can influence some aspects of neuronal phenotype [e.g., neuronal survival (Calderó et al., 1998), peptide expression (McMahon and Gibson, 1987), central connectivity (Wenner and Frank, 1995)], we asked whether innervation of older, more mature targets that occurs after heterochronic limb transplantation would accelerate neuronal maturation.

\section{Programmed cell death}

For example, programmed cell death of motor and sensory neurons normally is regulated by their peripheral targets (Hollyday and Hamburger, 1976; Carr and Simpson, 1978; Calderó et al., 1998). We found that fewer healthy motor and sensory neurons and more apoptotic neurons innervated older donor limbs than innervated the control limb in the same embryo. Several lines of evidence 

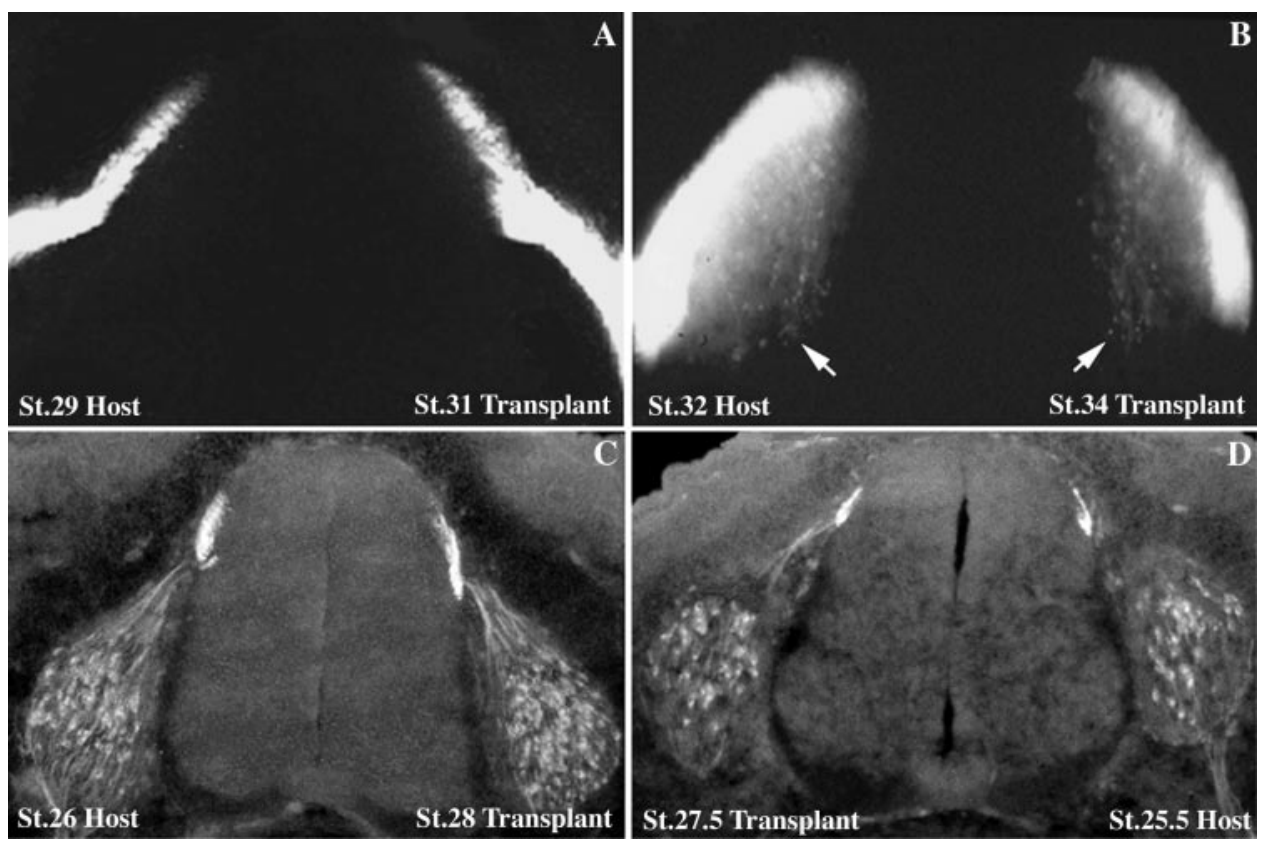

Figure 7. Neither the development of central projections nor the biochemical maturation of sensory neurons is accelerated by premature innervation of peripheral targets. $A$, Sensory neurons that innervate an older donor limb (St. 31) do not invade the dorsal horn in advance of neurons innervating the host (St. 29) limb. B, The central projection of sensory neurons (arrows) that innervate a St. 34 transplanted limb are indistinguishable from those of neurons innervating the St. 32 host limb. $C, D$, There is no obvious difference in expression of either substance $\mathrm{P}(C)$ or trkA $(D)$ in DRGs innervating transplanted and host limbs, although the donor limbs are approximately two stages older. indicate that these differences reflect the precocious onset of cell death. First, decreased production of neurons is unlikely to contribute to the observed differences because the periphery does not appear to influence neuron proliferation (Hollyday and Hamburger, 1976; Calderó et al., 1998). Second, neuron number was not altered in sham-operated embryos. Third, the numbers of surviving motor neurons on each side of operated embryos were similar to values previously reported for embryos of the same age as the respective limbs (Calderó et al., 1998). Finally, the overall pattern of neuronal survival, as described in Results, mirrored the general rostrocaudal progression of cell death (Gould et al., 1999). Such consistencies would not be expected if the reduction in neuron number were an artifact of surgery.

Why does innervation of older donor limbs trigger the early onset of neuronal cell death? The most parsimonious explanation is that axons that innervate older donor limbs contact peripheral targets earlier than usual. During normal development the neurons require target-derived neurotrophic factors for survival (Oppenheim, 1991). Production of neurotrophic factors and neuronal dependence on these factors first appear at approximately the time that axons contact peripheral targets (Davies et al., 1987; Vogel and Davies, 1991). In vitro, premature exposure to neurotrophic factors triggers premature dependence on these factors (Vogel and Davies, 1991). Thus, in our experiments the precocious innervation of transplanted limbs most likely caused the precocious dependence of host neurons on limb-derived trophic factors, thereby accelerating the onset of naturally occurring cell death.

\section{Central projections and biochemical maturation of sensory neurons}

During normal development sensory neurons also observe a waiting period before projecting to targets in the spinal cord (Lee et al., 1988; Davis et al., 1989; Sharma et al., 1994). This waiting period was still observed by sensory neurons in operated embryos. Central projections developed on schedule and were not accelerated by premature innervation of older donor limbs. This perhaps is not surprising, because cells in the dorsal horn express inhibitory molecules such as collapsin (Shepherd et al., 1996, 1997) when sensory axons first arrive there. Growth-promoting molecules such as slit2 protein (Wang et al., 1999) begin to appear and collapsin disappears (Shepherd et al., 1996, 1997) at approximately the time that axons invade the gray matter. Whereas it is clear that peripheral targets can determine the central connections of sensory neurons (Wenner and Frank, 1995), our results show that precocious innervation of these targets does not promote sufficient maturation of either sensory neurons or the spinal cord to accelerate the establishment of central connections.

Similarly, expression of substance $\mathrm{P}$ and trkA in DRG neurons was not obviously enhanced by innervating the older donor limbs. This finding is surprising in light of the observation that the peripheral target can regulate expression of substance $\mathrm{P}$ in mature animals (McMahon and Gibson, 1987). What normally triggers expression of substance $\mathrm{P}$ is unknown. Our results with trkA, however, are consistent with the observation that expression of trkA in developing sensory neurons is not modulated by NGF (Davies et al., 1995), which normally is produced by targets of NGF-dependent neurons. Further experiments will be necessary to elucidate the mechanisms and signals that regulate the appearance of these biochemical markers in sensory neurons. Clearly, simple contact with a peripheral target is not sufficient.

Much is still unknown about target influences on neuronal differentiation. Here we have shown that our ability to manipulate the relative timing of target innervation can be exploited to discriminate between direct target-related and intrinsic events in neuronal development. The molecular signals responsible for target influences remain to be elucidated.

\section{REFERENCES}

Araujo M, Piedra ME, Herrera MT, Ros MA, Nieto AM (1998) The expression and regulation of chick EphA7 suggests roles in limb patterning and innervation. Development 125:4195-4204.

Calderó J, Prevette D, Mei X, Oakley RA, Li L, Milligan C, Houenou L, Burek M, Oppenheim RW (1998) Peripheral target regulation of the development and survival of spinal sensory and motor neurons in the chick embryo. J Neurosci 18:356-370.

Carr VM, Simpson Jr SB (1978) Proliferative and degenerative events in the early development of chick dorsal root ganglia. II. Responses to altered peripheral fields. J Comp Neurol 182:741-755.

Clarke PGH, Oppenheim RW (1995) Neuron death in vertebrate development: in vivo methods. In: Methods in cell biology. Cell death (Schwartz L, Osborne B, eds), pp 277-321. New York: Academic.

Davies AM, Bandtlow C, Heumann R, Korsching S, Rohrer H, Thoenen H (1987) Timing and site of nerve growth factor synthesis in developing skin in relation to innervation and expression of the receptor. Nature 326:353-358.

Davies AM, Wyatt S, Nishimura M, Phillips H (1995) NGF receptor expression in sensory neurons develops normally in embryos lacking NGF. Dev Biol 171:434-438.

Davis BM, Frank E, Johnson FA, Scott SA (1989) Development of central projections of lumbosacral sensory neurons in the chick. J Comp Neurol 279:556-566.

Gould TW, Burek MJ, Sosnowski JM, Prevette D, Oppenheim RW (1999) 
The spatial-temporal gradient of naturally occurring motor neuron death reflects the time of prior exit from the cell cycle and position within the lateral motor column. Dev Biol 216:611-621.

Hamburger V, Hamilton HL (1951) A series of normal stages in the development of the chick embryo. J Morphol 88:49-92.

Hollyday M, Hamburger V (1976) Reduction of the naturally occurring motor neuron loss by enlargement of the periphery. J Comp Neurol 170:311-320.

Honig MG, Frase PA, Camilli SJ (1998) The spatial relationships among cutaneous, muscle sensory and motoneuron axons during development of the chick hindlimb. Development 125:995-1004.

Johnson GD, Nogueira Araujo GM (1981) A simple method of reducing the fading of immunofluorescence during microscopy. J Immunol Methods 43:349-350.

Lance-Jones C, Landmesser L (1981) Pathway selection by chick lumbosacral motoneurons during normal development. Proc R Soc Lond [Biol] 214:1-18.

Landmesser L (1988) Peripheral guidance cues and the formation of specific motor projections in the chick. In: From message to mind (Easter SSJ, Barald KF, Carlson BM, eds), pp 121-133. Sunderland, MA: Sinauer.

Landmesser L (1994) Axonal outgrowth and pathfinding. In: Progress in brain research (Seil FJ, ed), pp 67-73. New York: Elsevier.

Landmesser L, Honig MG (1986) Altered sensory projections in the chick hind limb following the early removal of motoneurons. Dev Biol 118:511-531.

Lee MT, Koebbe MJ, O'Donovan MJ (1988) The development of sensorimotor synaptic connections in the lumbosacral cord of the chick embryo. J Neurosci 8:2530-2543.

Lentz SI, Miner JH, Sanes JR, Snider WD (1997) Distribution of the ten known laminin chains in the pathways and targets of developing sensory axons. J Comp Neurol 378:547-561.

McMahon SB, Gibson S (1987) Peptide expression is altered when afferent nerves reinnervate inappropriate tissue. Neurosci Lett 73:9-15.

New HV, Mudge AW (1986) Distribution and ontogeny of SP, CGRP, SOM, and VIP in chick sensory and sympathetic ganglia. Dev Biol 116:337-346.

Oakley RA, Tosney KW (1991) Peanut agglutinin and chondroitin-6sulfate are molecular markers for tissues that act as barriers to axon advance in the avian embryo. Dev Biol 147:187-206.

Oppenheim RW (1991) Cell death during development of the nervous system. In: Annual review of neuroscience (Cowan WM, Shooter EM, Stevens CF, Thompson RF, eds), pp 453-501. Palo Alto, CA: Annual Reviews.

Scott SA (1984) The effects of neural crest deletions on the development of sensory innervation patterns in embryonic chick hind limb. J Physiol (Lond) 352:285-304.

Scott SA (1988) Skin sensory innervation patterns in embryonic chick hindlimbs deprived of motoneurons. Dev Biol 126:362-374.
Scott SA, editor (1992a) Sensory Neurons: Diversity, Development, and plasticity. New York: Oxford UP.

Scott SA (1992b) The development of peripheral sensory innervation patterns. In: Sensory Neurons: Diversity, Development, and Plasticity (Scott SA, ed), pp 242-263. New York: Oxford UP.

Scott SA, Wang GY (1999) Effects of premature target innervation on the development of sensory and motor neurons in the chick hindlimb. Soc Neurosci Abstr 25:1792.

Sharma K, Korade Z, Frank E (1994) Development of specific muscle and cutaneous sensory projections in cultured segments of spinal cord. Development 120:1315-1323.

Shatz CJ, Ghosh A, McConnell SK, Allendoerfer KL, Friauf E, Antonini A (1990) Pioneer neurons and target selection in cerebral cortical development. Cold Spring Harb Symp Quant Biol 55:469-480.

Shepherd I, Luo YL, Raper JA, Chang S (1996) The distribution of collapsin-1 mRNA in the developing chick nervous system. Dev Biol 173:185-199.

Shepherd IT, Luo Y, Lefcort F, Reichardt LF, Raper JA (1997) A sensory axon repellent secreted from ventral spinal cord explants is neutralized by antibodies raised against collapsin-1. Development 124:1377-1385.

Swanson GJ, Lewis J (1982) The timetable of innervation and its control in the chick wing bud. J Embryol Exp Morphol 71:121-137.

Tosney KW, Landmesser LT (1985a) Development of the major pathways for neurite outgrowth in the chick hindlimb. Dev Biol 109:193-214.

Tosney KW, Landmesser L (1985b) Growth cone morphology and trajectory in the lumbosacral region of the chick embryo. J Neurosci 5:2345-2358.

Tosney KW, Landmesser LT (1985c) Specificity of early motoneuron growth cone outgrowth in the chick embryo. J Neurosci 5:2336-2344.

Vogel KS, Davies AM (1991) The duration of neurotrophic factor independence in early sensory neurons is matched to the time course of target field innervation. Neuron 7:819-830.

Wang GY, Scott SA (1999a) Sensory and motor axons pause independently in the plexus region and exit in response to cues derived from the limb. Soc Neurosci Abstr 25:1792.

Wang GY, Scott SA (1999b) Independent development of sensory and motor innervation patterns in embryonic chick hindlimbs. Dev Biol 208:324-336.

Wang KH, Brose K, Arnott D, Kidd T, Goodman CS, Henzel W, TessierLavigne M (1999) Biochemical purification of a mammalian slit protein as a positive regulator of sensory axon elongation and branching. Cell 96:771-784.

Wenner P, Frank E (1995) Peripheral target specification of synaptic connectivity of muscle spindle sensory neurons with spinal motoneurons. J Neurosci 15:8191-8198.

Wright DE, White FA, Gerfen RW, Silos-Santiago I, Snider WD (1995) The guidance molecule semaphorin III is expressed in regions of spinal cord and periphery avoided by growing sensory axons. J Comp Neurol 361:321-333. 